\title{
Bladder and sexual function following resection of rectal cancer
}

\author{
An Essay \\ submitted for partial fulfillment of master degree \\ in general surgery
}

By

Mahmoud Ali Ali Matter

M.B., B.CH

\begin{abstract}
Under Supervision of
Professor Dr. Ali Thabet

Professor of General Surgery

Faculty of Medicine - Ain Shams University

Professor Dr. Amr Fekry El-Shorbagy

Assistant Professor of Urology

Faculty of Medicine - Ain Shams University

Dr. Ahmed Mohamed Nafei

Lecturer of General Surgery

Faculty of Medicine - Ain Shams University
\end{abstract}

Faculty of Medicine

Ain Shams University

2008 


\begin{abstract}
Total mesorectal excision with pelvic autonomic nerve preservation (TME-ANP) has been reported to be an optimal surgery for rectal cancer. It minimizes local recurrence and sexual and urinary dysfunction. There is a device (CaverMapA Device) that has the potential ability to enhance pelvic autonomic nerve identification and preservation during rectal surgery. Erectile dysfunction after rectal excision for rectal cancer is completely reversed or satisfactorily improved in 79 percent of patients after use of sildenafil. This means that these patients have an excellent chance of improvement in their erectile function with sildenafil.
\end{abstract}

\section{Summary:}

The primary aims of rectal cancer surgery are to achieve oncological clearance of the tumor, to minimize local recurrence and to prolong survival. Accurate preoperative staging and precise surgical technique using the principles of total mesorectal excision (TME) are instrumental in achieving this goal. however, Quality of life must not be forgotten in the quest for oncological excellence. Postoperative urinary and sexual dysfunction resulting from inadvertent damage to the pelvic hypogastric and splanchnic nerves are recognized complications of rectal resection. ${ }^{1}$

The pelvic autonomic nerves consist of the paired hypo-gastric (sympathetic), sacral (parasympathetic), and inferior hypogastric nerves. Sympathetic nerves originate from L1L3 form the inferior mesenteric plexus, travel through the superior hypogastric plexus and descend as the hypogastric nerves to the pelvic plexus. The parasympathetic nerves, or nervi erigentes, arise from $\mathrm{S} 2-\mathrm{S} 4$ and join the hypogastric nerves anterior and lateral to the rectum to form the pelvic plexus and ultimately the periprostatic plexus. The inferior hypogastric nerve plexus arises from interlacing sympathetic and parasympathetic nerve fibers and forms a fenestrated rhomboid plate on the lateral pelvic sidewall. Fibers from this plexus innervate the rectum as well the bladder, ureter, prostate, seminal vesicles, membranous urethra, and corpora cavernosa, Therefore, injury to these autonomic nerves can lead to impotence, bladder dysfunction, and loss of normal defecatory mechanisms. ${ }^{2}$

There are four key zones of risk of autonomic nerve damage. The risk of sympathetic nerve damage occurs in the abdomen during ligation of the inferior mesenteric artery pedicle, and high in the pelvis during initial posterior rectal dissection adjacent to the large hypogastric nerves. Lower down, risk to the parasympathetic nerves occurs while dissecting laterally near the pelvic plexus, and during deep dissection of the anterior aspect of the rectum away from the seminal vesicles and prostate near the cavernous nerves. ${ }^{3}$

Total mesorectal excision (TME) in conjunction with low anterior resection (LAR) or abdominoperineal resection (APR) involves precise dissection and removal of the entire rectal mesentery, including that distal to the tumor, as an intact unit. Unlike conventional blunt dissection, which may leave residual in the pelvis, TME involves sharp dissection under direct vision in the avascular, areolar plane between the fascia propria of the rectum, which encompasses the mesorecum, and the parietal fascia overlying the pelvic wall structures. Post operative impotence, retrograde ejaculation, or both are observed in $25-75 \%$ of conventionally treated patients compared with only $10-29 \%$ of patients after TME with its careful nerve sparing dissection. Also, in a prospective study of rectal cancer patients under going TME, only 2 of 35 had difficulty with bladder emptying. ${ }^{2}$

CaverMap ${ }^{\circledR}$ Device $(\mathrm{CM})$ is a device combines a nerve stimulator with an erectile response detection system for intraoperative use. CM was a useful tool in objectively confirming the preservation of the autonomic nerves in 27 (93 percent) patients, at least unilaterally, at the end of the procedure and CM is approved by the U.S. Food and Drug. ${ }^{4}$

Erectile dysfunction after rectal excision for rectal cancer is completely reversed or satisfactorily improved in 79 percent of patients after use of sildenafil. This means that these patients have an excellent chance of improvement in their erectile function with 
sildenafil. These findings also suggest that erectile dysfunction after rectal excision is caused by partial parasympathetic neural injuiry. 5

\section{References:}

1- Jayne DG, Brown JM, Thorpe H, Walker J, Quirke P, Guillou PJ: Bladder and sexual function following resection for rectal cancer in a randomized clinical trial of laparoscopic versus open technique. $\mathrm{Br} \mathrm{J}$ Surg 2005; 92: 1124-1132.

2- Dalal KM, Bleday R: Cancer of the rectum. In Maingot abdominal operations. Zinner MJ, Ashley SW (Editors); The McGrawHill (Publisher), 11 edn. 2007; p. 693-725.

3- Chang AE, Morris AM: Colorectal cancer. In: Greenfield's surgery. Mulholland MW, Lillemoe KD (Editors); Lippincott Williams \&Wilikins (Publishers); 4th edn. 2006; p.1103-1129.
4- Giovanna M, Zmora O, Börjesson L: The efficacy of a nerve stimulator (Cavermap $\left.{ }^{\circledR}\right)$ to enhance autonomic nerve identification and confirm nerve preservation during total mesorectal excision. Dis Colon Rectum 2004; 47: 2032-2038.

5- Lindsey I, George B, Kettlewell M: Randomized, Double-blind, trial of sildenafil for erectile dysfunction after rectal excision for cancer and inflammatory bowel disease. Dis Colon Rectum 2002; 45: 727-732. 


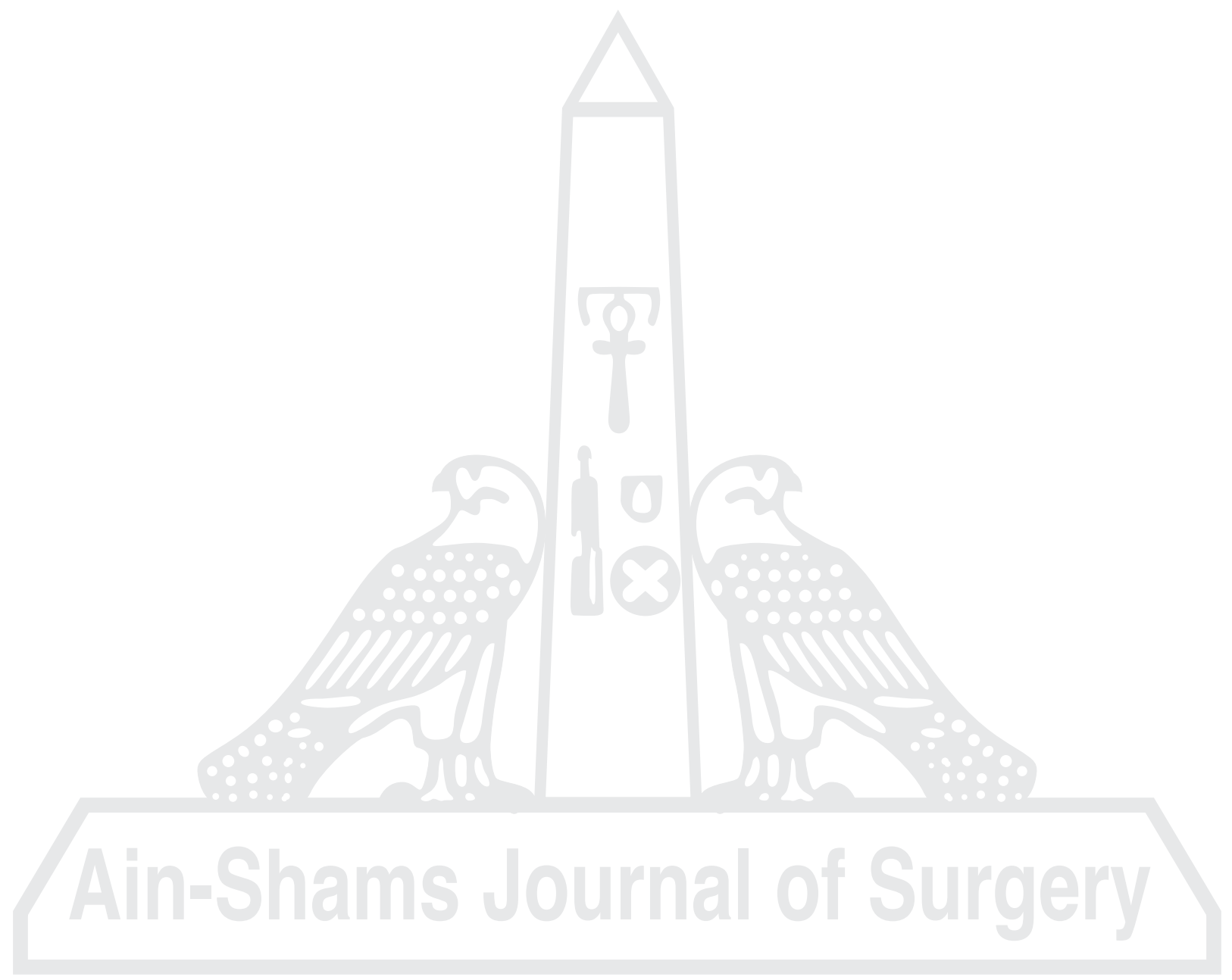

